\title{
A preliminary case study of androgen receptor gene polymorphism association with impulsivity in women with alcoholism
}

This article was published in the following Dove Press journal:

Advances in Genomics and Genetics

3 March 2014

Number of times this article has been viewed

\section{Daniel J Mettman \\ Merlin G Butler \\ Albert B Poje \\ Elizabeth C Penick \\ Ann M Manzardo}

Departments of Psychiatry and Behavioral Sciences and Pediatrics, MS 40I5, Kansas University Medical Center, Kansas City, KS, USA
Correspondence: Ann M Manzardo Departments of Psychiatry and Behavioral Sciences, MS 4015, Kansas University Medical Center, 390I Rainbow Blvd, Kansas City, KS, 66160, USA

$\mathrm{Tel}+\mathrm{I} 9135886473$

Fax +19135881305

Email amanzardo@kumc.edu
Objective: The androgen receptor $(A R)$ gene, located on the $\mathrm{X}$ chromosome, contains a common polymorphism involving cytosine-adenine-guanine (CAG) repeats, which impacts disease and could contribute to the unequal sex ratio in alcoholism. CAG repeats in the $A R$ gene are known to correlate with impulsivity in males. We report the first preliminary study examining the association between the number of CAG repeats and measures of impulsivity in females with chronic alcoholism.

Methods: A total of 35 women and 85 men with chronic alcoholism were previously recruited for a nutritional clinical trial, and 26 well-characterized females (19 African-American and seven Caucasian) with alcoholism agreed to participate for genetic testing. Genomic deoxyribonucleic acid (DNA) was isolated from peripheral blood and CAG repeats determined by analyzing polymerase chain reaction (PCR)-amplified products, using the polymorphic $A R$ gene assay. CAG repeat length was correlated with raw scores from the Barratt Impulsivity Scale, version 11 and the Alcoholism Severity Scale.

Results: CAG repeat lengths were significantly longer in Caucasian alcoholic women compared with African-Americans, and the average number of CAG repeats were significantly, positively correlated $(P<0.05)$ with impulsivity scores. Women with average CAG repeat length $\left(\mathrm{CAG}_{\text {ave }}\right) \geq 18$, representing the upper quartile of the repeat range, showed significantly greater mean raw impulsivity scores. CAG repeat length appeared to have less effect in African-American compared with Caucasian women, possibly due to a shorter average repeat length.

Conclusion: We found an association between the number of CAG repeats and impulsivity in females with chronic alcoholism, specifically in women with $\mathrm{CAG}_{\text {ave }} \geq 18$, seen more commonly in Caucasian compared with African-American women.

Keywords: $A R$ gene, CAG repeat, African-American, Caucasian, behavior

\section{Introduction}

Alcoholism is a highly prevalent mental disorder that affects millions of people worldwide and is associated with significant personal and global economic costs to society. ${ }^{1-3}$ Alcohol-use disorders can be distinguished from normal alcohol use by the reduced ability to control or limit alcohol consumption to moderate amounts after initiation of drinking. ${ }^{4,5}$ Alcohol dependence can result in the onset of withdrawal symptoms, such as anxiety, irritability, sweating, tremors, and hallucinations, with abstinence. ${ }^{6}$ Excessive alcohol consumption can lead to a decline in physical and mental health, unemployment, legal troubles, and social isolation. ${ }^{3-5}$

The cause of alcoholism is believed to be multifactorial and attributable to both genetic and environmental factors. Genetic influences are estimated to account for $\sim 50 \%$ 
of the risk. ${ }^{7}$ A possible role of genes on the $\mathrm{X}$ chromosome in contributing to alcoholism is suggested by the uniformly higher prevalence rates for males, who are two to three times more likely to develop alcoholism than females. ${ }^{8}$ There are several mechanisms whereby X-linked gene variants may influence the risk for alcoholism in females (in addition to recessive or dominant inheritance patterns). Nonrandom skewness of $\mathrm{X}$ chromosome inactivation (XCI), which is defined as greater than $80 \%: 20 \%$ preferential inactivation of one of the two X chromosomes, could lead to overexpression of X-linked gene variants that increase the risk of alcoholism. However, in one study, deoxyribonucleic acid (DNA) isolated from peripheral blood in females with alcoholism did not show evidence of nonrandom XCI skewness. ${ }^{9}$ The X chromosome also contains the androgen receptor $(A R)$ gene, located at the Xq11-q12 band, which codes for production of the androgen receptor, a gene of interest in alcoholism research and a focus of the present study.

Androgens and the androgen receptor play a role in establishing sex differences in mammals. Testosterone, a ligand for the androgen receptor, is responsible for the physiological differences between men and women and could contribute to sex disparity in the incidence of alcoholism - a correlation exists between alcoholism and behavioral traits thought to be controlled by testosterone, including impulsiveness. For example, free testosterone levels positively correlate with impulsiveness in normal males and have been linked to the initiation and continuation of alcohol consumption, the degree of reward induced by alcohol, and development of alcohol abuse disorders. ${ }^{10-14}$ Impulsiveness could predispose to alcoholism or alcoholism could affect changes that increase impulsiveness, but an independent factor - such as levels of free testosterone - could also explain this association in males. A paucity of data exists regarding the relationship between androgen receptor function and impulsiveness in females.

The first exon of the $A R$ gene contains a tract of polymorphic cytosine-adenine-guanine (CAG) triplet repeats that in normal individuals ranges from eight to 35 repeats. ${ }^{15}$ Variations in the number of CAG repeats influence $A R$ receptor expression and androgen sensitivity in both sexes, with fewer numbers of CAG repeats associated with increased $A R$ gene expression and greater sensitivity to androgens. ${ }^{16}$ When the length of the polyglutamine tract in the $A R$ gene exceeds 40 repeats, then the $A R$ gene transcription is altered, leading to development of spinal bulbar muscular atrophy (SBMA). ${ }^{15}$ SBMA results from the ligand-dependent nuclear accumulation of the polyglutamine-expanded AR protein, which is neurotoxic. Specific pathogenesis of SBMA is modified by additional factors, such as DNA-binding, interdomain interactions, and posttranslational modification of AR. ${ }^{16}$ Even within the normal range, $A R$ gene polymorphisms are associated with variations in androgen sensitivity, which correlate with neurological and endocrine problems, including the risk of developing prostate and breast cancer and infertility. ${ }^{15,16}$ The impact of chronic alcoholism on the nuclear accumulation of the polyglutamine-expanded AR protein or the pathogenesis of SBMA is presently unknown but may impact upon the symptomology and/or disease course with advancing age.

CAG repeat length influences testosterone levels in men and women, with shorter repeats typically associated with higher testosterone levels in females. ${ }^{17-19}$ However, testosterone levels are influenced by many factors, including negative feedback mechanisms through the $A R$ gene, which may be reduced at longer CAG repeat lengths $(>24) .{ }^{20}$ Previous studies have reported differences in the length of $A R$ CAG repeats in races, with blacks (African-Caribbean) having shorter CAG repeats (highest frequency allele $=18$ repeats) than Caucasians (highest frequency allele $=21$ repeats) and Hispanics (highest frequency allele $=22$ repeats). ${ }^{16}$

In the present study, we examined correlations between the length of the CAG tract of the $A R$ gene and alcoholism in females. The length of the polyglutamine tract and impulsivity have been inversely related in males, ${ }^{21-24}$ but to our knowledge, no data are available describing the relationship between the size of the $A R$ allele and impulsivity or the $A R$ $\mathrm{CAG}$ repeat length and alcoholism in females. We sought to provide additional insight into the correlation between $\mathrm{CAG}$ repeat length of the $A R$ gene and alcoholism by comparing the repeat lengths with measures of alcoholism and psychiatric severity, in a cohort of well-characterized African-American and Caucasian alcoholic females.

\section{Materials and methods Subjects}

A total of 120 self-identified women $(\mathrm{N}=35)$ and men $(\mathrm{N}=85)$ with chronic alcoholism were recruited from the Greater Kansas City Metropolitan Area for a clinical trial on nutritional supplements, and 26 well-characterized females agreed to participate for genetic testing. ${ }^{25}$ These included 19 AfricanAmerican and seven Caucasian women whose ages ranged from 25 to 56 years with an average age of $43.2 \pm 8.3$ years. All females met the diagnostic criteria for Alcohol Dependence, according to the Diagnostic and Statistical Manual of Mental Disorders, fourth edition (DSM-IV). ${ }^{5}$ There was no difference 
in age between the African-American and Caucasian women ( $F=0.07 ; P=0.79)$. On average, the females had consumed alcohol 4 days each week during the previous 6 months before entering the study. On 3 of the 4 drinking days, they averaged more than 4 ounces of alcohol a day. A total of $92 \%$ reported a family history of alcoholism, 89\% had either previously used or were currently using tobacco, and 70\% had either previously used or were currently using illicit drugs. This study was conducted under the authority of the University of Kansas Medical Center, Office of Research Compliance, which reviewed the study protocol and monitored study activities to ensure that appropriate steps were taken to protect the rights and welfare of the individuals participating as research subjects.

\section{Clinical and behavioral assessment}

Following the initial screening procedure at baseline, a comprehensive interview was performed to determine final study eligibility based upon DSM-IV-R diagnostic criteria for Alcohol Dependence. The psychosocial interview was precoded and structured with high test-retest reliability and administered by a trained research nurse. This interview included the 33-item Alcoholism Severity Scale; ${ }^{26}$ the Symptom Checklist-90-R (SCL-90-R) which assesses psychiatric symptomology in the past week; and the Barratt Impulsivity Scale, version 11 (BIS-11), a highly cited psychological test for impulsiveness and previously used in alcoholic subjects. ${ }^{12,27,28}$ The BIS-11 contains 30 items that subjects are asked to rate in terms of how precisely the statements apply to themselves. The four response choices are "rarely/never", "occasionally", "often", and "almost always/always". Each statement is intended to glean information relevant to a particular facet of impulsivity, for six first-order factors (attention, motor, self-control, cognitive complexity, perseverance, and cognitive instability impulsiveness), three second-order factors (attentional, motor, and nonplanning impulsiveness), and total impulsiveness. The SCL-90-R is one of the most commonly used instruments for measuring psychological distress and consists of a 90-item questionnaire that yields scores for nine primary symptom dimensions (somatization, obsession compulsion, interpersonal sensitivity, depression, anxiety, hostility, phobic anxiety, paranoid ideation, and psychoticism) as well as a global severity index.

\section{Androgen receptor gene assay}

The $A R$ gene is located at the Xq11-q12 chromosome band and has a high degree of polymorphism (about 90\%). The number of CAG repeats of the $A R$ gene was determined through analysis of DNA isolated from peripheral blood, as previously described, and was available for each female reported in this study. ${ }^{9}$ DNA was isolated from blood samples using the MasterPure ${ }^{\mathrm{TM}}$ DNA Purification Kit (Epicentre Biotechnologies, Madison, WI, USA), and 200 ng of DNA from each study participant was digested with the methylsensitive restriction enzyme HpaII in the manner described by Allen et $\mathrm{al}^{29}$ which preferentially digests active (unmethylated) DNA over inactivate (methylated) DNA. The HpaII-treated DNA was then amplified by polymerase chain reaction (PCR) with a PTC 100 Programmable Thermal Controller (Bio-Rad Laboratories, Hercules, CA, USA), using DNA sequences 5' TCCAGAATCTGTTCCAGAGCGTGC 3' which were fluorescently labeled with 6-carboxyfluorescein as the forward primer, and 5' GCTGTGAAGGTTGCTGTTCCTCAT $3^{\prime}$ as the reverse primer. The length and amount of each fragment were determined with the use of capillary electrophoresis and an ABI Prism ${ }^{\circledR} 3100$ DNA sequencer (Applied Biosystems, Carlsbad, CA, USA) as previously described. ${ }^{30,31}$ To account for potential differences in allele amplification and to ensure reproducibility, up to three replications were performed for each sample. Since the CAG repeat is located and DNA-amplified between the two PCR primers for the $A R$ gene, the length differences between separate PCR fragments would be attributed to differences in the number of $\mathrm{CAG}$ repeats. The amounts of digested and undigested fragments were measured for each allele from the differences in PCR peak heights recorded in the digested and undigested DNA fragment aliquots and the XCI status determined for each $\mathrm{X}$ chromosome represented by the two polymorphic AR alleles.

The number of CAG repeats in the allele represented by the shorter PCR fragment (termed CAGS) and the number of CAG repeats in the allele represented by the longer PCR fragment (termed CAGL) were averaged across subjects. The average overall $\mathrm{CAG}\left(\mathrm{CAG}_{\text {ave }}\right)$ repeat length was calculated from the mean of CAGS and CAGL. The $\mathrm{CAG}_{\text {ave }}$ was also categorized as those falling above and below the upper quartile range (75th centile) ( $\geq 18 \mathrm{CAG}$ repeats). $\mathrm{SAS}^{\circledR} 9.2$ statistical analysis software (SAS Institute Inc., Cary, NC, USA) was then used to calculate descriptive statistics and interrelationships between outcome measures, using nonparametric Spearman's rank correlation coefficient $(\rho)$. Bonett and Wright $^{32}$ used a two-stage approximation method to assess the sample size needed to identify significant associations using Spearman rank correlations and found $\mathrm{N}=16$ was sufficient to identify strong correlations $(\rho>0.9)$ at $\alpha<0.05$ significance level, depending on the sample variance. Linear regression 
analysis with Bonferroni correction for multiple testing was used to compare group means. Due to racial differences in AR CAG repeat length, ${ }^{16,32}$ African-American and Caucasian female alcoholics were analyzed separately and as a group.

\section{Results}

\section{CAG repeat length}

The overall $\mathrm{CAG}_{\mathrm{ave}} \pm$ standard deviation (SD) for study females was 16.9 \pm 1.75 ; range: $13.5-20.5$, which is within the normative CAG repeat range of eight to 35 repeats. ${ }^{15} \mathrm{The}^{\mathrm{CAG}}$ ave was within normal range for the 19 African-American and seven Caucasian women (Figure 1), although it was shorter than the normative population $\mathrm{CAG}$ repeat length estimates (average $\pm \mathrm{SD})$ for nonalcoholics in both racial groups (21.9 \pm 2.8 in whites and $19.7 \pm 3.1$ in blacks). ${ }^{16}$ In agreement with previous reports, ${ }^{16,33,34}$ we found that the mean polyglutamine CAG repeat tract in exon 1 of the $A R$ gene was significantly shorter in African-American (16.5 \pm 1.65 ; range: 13.5-19.5) than in Caucasian females with alcoholism (18.1 \pm 1.52 ; range: 16.5-20.5) ( $F=5.27 ; P=0.03)$ (Table 1). The mean CAGS was also significantly shorter in African-American (14.8 \pm 1.61 ;

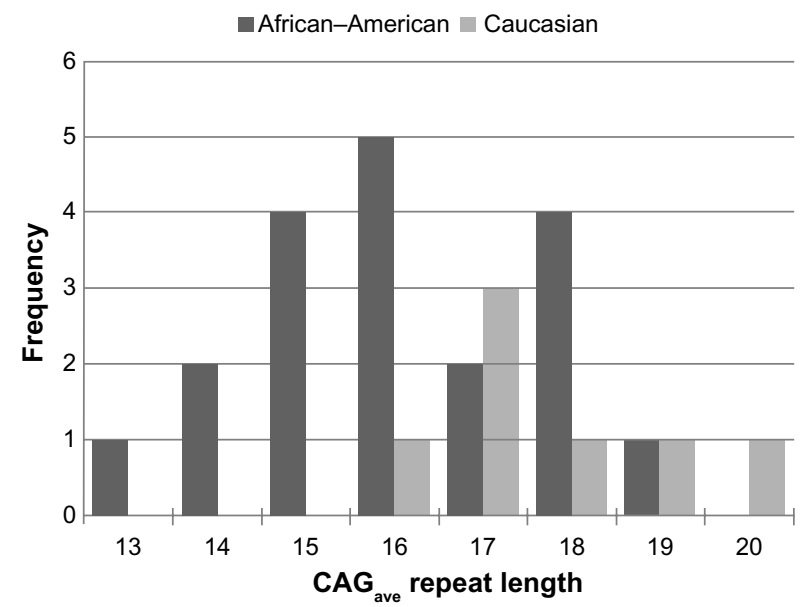

Figure I Histogram illustrating the frequency distribution of average CAG repeat lengths observed in African-American ( $N=19)$ relative to Caucasian $(\mathrm{N}=7)$ women with alcoholism.

Abbreviations: CAG, cytosine-adenine-guanine polymorphism; $\mathrm{CAG}_{\text {ave }}$, average CAG repeat length. range: $12-18)$ than in Caucasian females (16.7 \pm 2.06 ; range: 15-20) with alcoholism $(F=5.98 ; P=0.02)$. The relationship between the percent inactivation of the CAGS and race did not meet statistical significance $(F=2.28 ; P=0.14)$, with the tendency to inactivate the shorter allele at approximately a 50:50 ratio for both races. Further, no significant difference in the degree of XCI skewing was observed between races.

\section{Psychiatric severity}

As expected, our alcohol-dependent females scored significantly higher than the standardized norms (84th centile) for nonpsychiatric populations using the SCL-90-R (Figure 2) and BIS-11 instruments, indicating a significant level of psychiatric distress and elevated levels of impulsivity. ${ }^{11,35}$ No significant differences were observed between AfricanAmerican and Caucasian alcoholic females when comparing the BIS-11 or most of the SCL-90-R subscales. African-Americans scored significantly higher on three of the nine SCL-90-R subscales: phobic anxiety, paranoid ideation, and psychoticism (Figure 2), but differences in the Global Severity Index (GSI) did not meet statistical significance. The mean lifetime alcoholism severity scores for African-Americans (22.8 \pm 3 .9; range: 16-31) did not differ significantly from those of Caucasians (22.7 \pm 7.4 ; range: 9-31) $(F=0.00 ; P=0.95)$, reflecting similarities in lifetime alcohol exposure.

\section{CAG repeat length, psychiatric severity, and impulsivity}

The length of CAG repeats (CAGS, CAGL, and $\mathrm{CAG}_{\text {ave }}$ ) of the $A R$ gene did not correlate with alcoholism severity or psychiatric severity, as measured by the SCL-90-R, for African-American or Caucasian females when considered separately or together. The percent inactivation of CAGS and shorter length of CAGS were significantly correlated with increased anxiety and paranoia symptoms among the African-American and Caucasian females, but the length of the CAG repeat did not appear to contribute broadly to

Table I The length of the CAG repeat in exon I of the androgen receptor gene by race, in females with alcohol dependence

\begin{tabular}{|c|c|c|c|c|c|c|c|c|}
\hline \multirow[t]{2}{*}{ Variable } & \multicolumn{2}{|c|}{ Overall $(\mathrm{N}=26)$} & \multicolumn{2}{|c|}{ African-American $(\mathrm{N}=19)$} & \multicolumn{2}{|c|}{ Caucasian $(\mathrm{N}=7)$} & \multirow[t]{2}{*}{ F-value } & \multirow[t]{2}{*}{$P$-value } \\
\hline & Mean \pm SD & Range & Mean \pm SD & Range & Mean \pm SD & Range & & \\
\hline CAGS & $15.3 \pm 1.9$ & $12-20$ & $|4.8 \pm 1.6|$ & $12-18$ & $16.7 \pm 2.06$ & $15-20$ & 5.98 & 0.02 \\
\hline CAGL & $18.5 \pm 2.4$ & $14-23$ & $18.2 \pm 2.52$ & $14-23$ & $19.6 \pm 1.62$ & $|7-2|$ & 1.88 & 0.18 \\
\hline$C A G_{\text {ave }}$ & $16.9 \pm 1.8$ & | 3.5-20.5 & $16.5 \pm 1.65$ & $13.5-19.5$ & $18.1 \pm 1.52$ & $16.5-20.5$ & 5.27 & 0.03 \\
\hline$\%$ Inact CAGS & $48.4 \pm 19.0$ & $16.6-86.9$ & $51.7 \pm 20.3$ & $16.6-86.9$ & $39.3 \pm 11.6$ & $27.9-56.2$ & 2.28 & 0.14 \\
\hline $\mathrm{XCl}$ skewness & $31.6 \pm 20.4$ & $2.2-73.8$ & $33.1 \pm 22.7$ & $2.2-73.8$ & $27.8 \pm 12.8$ & $10.5-44.3$ & 0.33 & 0.57 \\
\hline
\end{tabular}

Abbreviations: CAG, cytosine-adenine-guanine polymorphism; $\mathrm{CAG}_{\text {ave }}$, average $C A G$ repeat length; CAGL, long $A R$ allele; CAGS, short AR allele; Inact CAGS, inactivated CAGS; SD, standard deviation; $\mathrm{XCl}, \mathrm{X}$ chromosome inactivation. 


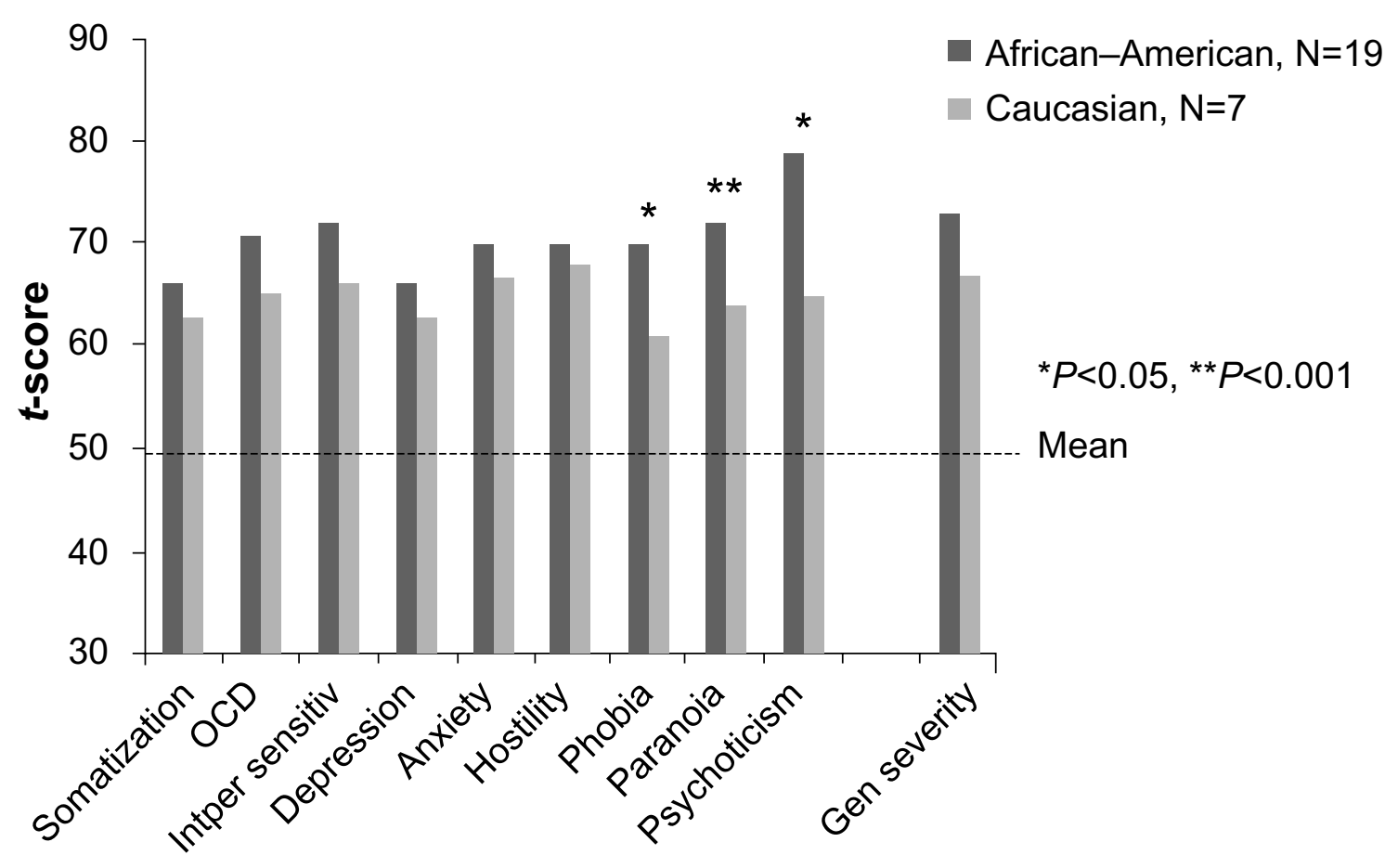

Figure 2 Symptom Checklist-90-R (SCL-90-R) normative scores for females by race relative to nonpsychiatric controls.

Notes: Normative SCL-90-R scores are derived from mean raw scores of $99 \%$ of the nonpsychiatric Caucasian female controls. Data are presented as area $t$-scores, with a mean $=50$ th centile and a standard deviation of I0. Mean $t$ scores were compared by race using a general linear model with a Bonferroni correction for multiple testing. Abbreviations: Gen severity, Global Severity Index; Intper sensitiv, interpersonal sensitivity; OCD, Obsessive-Compulsive Disorder.

alcoholic or psychiatric severity. However, examination of the BIS-11 raw scores among the alcoholic females as a group revealed a significant positive correlation between CAGL and $\mathrm{CAG}_{\text {ave }}$ with first- and second-order factors of the BIS-11. As shown in Table 2, CAGL was positively correlated with two of the six BIS-11 first-order factors, one of the three secondorder factors, and with total impulsiveness. This association appeared to reflect an effect in Caucasian females, where CAGL was positively correlated with four of the six BIS-11 first-order factors, two of the three second-order factors, and with total impulsiveness (Table 2). Several trends were also observed among African-American females but did not meet the criteria for statistical significance. A scatter plot of the correlation between CAG repeat length and BIS-11 raw scores illustrates the significant positive correlation between CAGL and Perseverance score, as seen in Figure 3, that was not observed for CAGS, which may be associated with a biological threshold at 18 repeats.

$\mathrm{CAG}_{\text {ave }}$-repeat data, categorized as those falling above and below the upper quartile range ( 75 th centile) ( $\geq 18 \mathrm{CAG}$ repeats), were analyzed using linear regression with a Bonferroni correction for multiple testing and controlling for the effects of race. Overall mean raw scores for the BIS-11 subscales were compared for (all 26) subjects with $\mathrm{CAG}_{\text {ave }} \geq 18$ repeats versus $\mathrm{CAG}_{\text {ave }}<18$ repeats. The results showed greater mean raw scores for three of the six BIS-11 first-order factors, two of the three second-order factors, and for total impulsiveness at $\mathrm{CAG}_{\mathrm{ave}} \geq 18$ (Figure 4). Significantly higher scores on the cognitive complexity $(t=-2.57$; $P<0.05)$, perseverance ( $t=-3.65 ; P<0.01$ ), motor impulsiveness $(t=-3.87 ; P<0.01)$, and nonplanning impulsiveness $(t=-2.58 ; P<0.05)$ subscales were observed for Caucasian women with $\mathrm{CAG}_{\mathrm{ave}} \geq 18$ repeats. Similarly, significantly higher scores on the cognitive complexity subscale $(t=-2.12$; $P<0.05)$ were observed for African-American females with $\mathrm{CAG}_{\mathrm{ave}} \geq 18$ repeats, suggesting that the association between impulsivity traits and $\mathrm{CAG}$ repeat length is not limited to an effect in Caucasian women.

\section{Discussion}

The present study provides a preliminary examination of the relationship between the CAG repeat length of exon 1 of the $A R$ gene and the severity of psychiatric distress and alcoholism in a group of severely alcohol dependent females. CAG repeat length was correlated with increased impulsivity but not psychiatric symptomology among alcohol-dependent women. Racial differences were observed that were consistent with previous reports identifying shorter average repeat lengths among African-American than Caucasian women. Women with average $\mathrm{CAG}$ repeat lengths in the upper quartile 
Table 2 Correlation between BIS-II raw scores and CAGL in women with alcohol dependence

\begin{tabular}{|c|c|c|c|c|c|c|}
\hline \multirow[t]{2}{*}{ Variable (raw scores) } & \multicolumn{2}{|l|}{ Overall } & \multicolumn{2}{|c|}{ African-American $(\mathrm{N}=19)$} & \multicolumn{2}{|c|}{ Caucasians $(\mathbf{N}=7)$} \\
\hline & $\begin{array}{l}\text { Spearman } \\
\text { coefficient }\end{array}$ & $P$-value & $\begin{array}{l}\text { Spearman } \\
\text { coefficient }\end{array}$ & $P$-value & $\begin{array}{l}\text { Spearman } \\
\text { coefficient }\end{array}$ & $P$-value \\
\hline \multicolumn{7}{|l|}{ BIS-I I first-order factors } \\
\hline Attention impulsiveness & 0.29 & 0.15 & 0.34 & 0.15 & 0.51 & 0.243 \\
\hline Motor impulsiveness & 0.30 & 0.13 & 0.16 & 0.50 & 0.85 & $0.02 *$ \\
\hline Self-control impulsiveness & 0.28 & 0.17 & 0.26 & 0.28 & 0.77 & $0.04^{*}$ \\
\hline Cognitive complexity & 0.41 & $0.04 *$ & 0.44 & 0.06 & 0.90 & $0.006 *$ \\
\hline Perseverance & 0.52 & $0.006 *$ & 0.42 & 0.07 & 0.96 & $0.0005^{*}$ \\
\hline Cognitive instability & 0.12 & 0.55 & 0.19 & 0.43 & 0.00 & 1.0 \\
\hline \multicolumn{7}{|l|}{ BIS-II second-order factors } \\
\hline Attentional impulsiveness & 0.22 & 0.27 & 0.29 & 0.22 & 0.26 & 0.574 \\
\hline Motor impulsiveness & 0.38 & $0.05^{*}$ & 0.21 & 0.38 & 0.96 & $0.0005^{*}$ \\
\hline Nonplanning impulsiveness & 0.37 & 0.06 & 0.40 & 0.09 & 0.82 & $0.02 *$ \\
\hline Total impulsiveness & 0.43 & $0.03 *$ & 0.41 & 0.08 & 0.78 & $0.04 *$ \\
\hline
\end{tabular}

Note: *Statistically significant $(P<0.05)$.

Abbreviations: BIS, Barratt Impulsivity Scale; CAG, cytosine-adenine-guanine polymorphism; CAGL, long AR allele.

range showed deficits in nonplanning and motor impulsivity, which reflect problems with attention to detail and acting without thinking. Correlations in these specific domains are indicative of nonspecific cognitive impairments commonly observed in alcoholism and may inform the underlying psychopathology or predict treatment response.

$A R$ gene allele length and androgen effects on behavior and psychopathology have been proposed to contribute to alcoholism and related personality traits and comorbidities, in males and females..$^{10,11,14,21,22}$ Previous studies have identified a relationship between a smaller number of CAG repeats and increased impulsivity in males. ${ }^{21-24}$ Impulsivity has also been associated with an increased risk of developing alcoholism in males and increased alcoholism severity, but a paucity of data exists regarding females. ${ }^{11,12}$ To our knowledge, there are no reports examining the influence of the CAG repeat length of the $A R$ gene on psychiatric outcomes in females.

Hormone disregulation attributable to the effects of alcohol has been associated with increased testosterone levels and masculinized phenotype in female alcoholics,

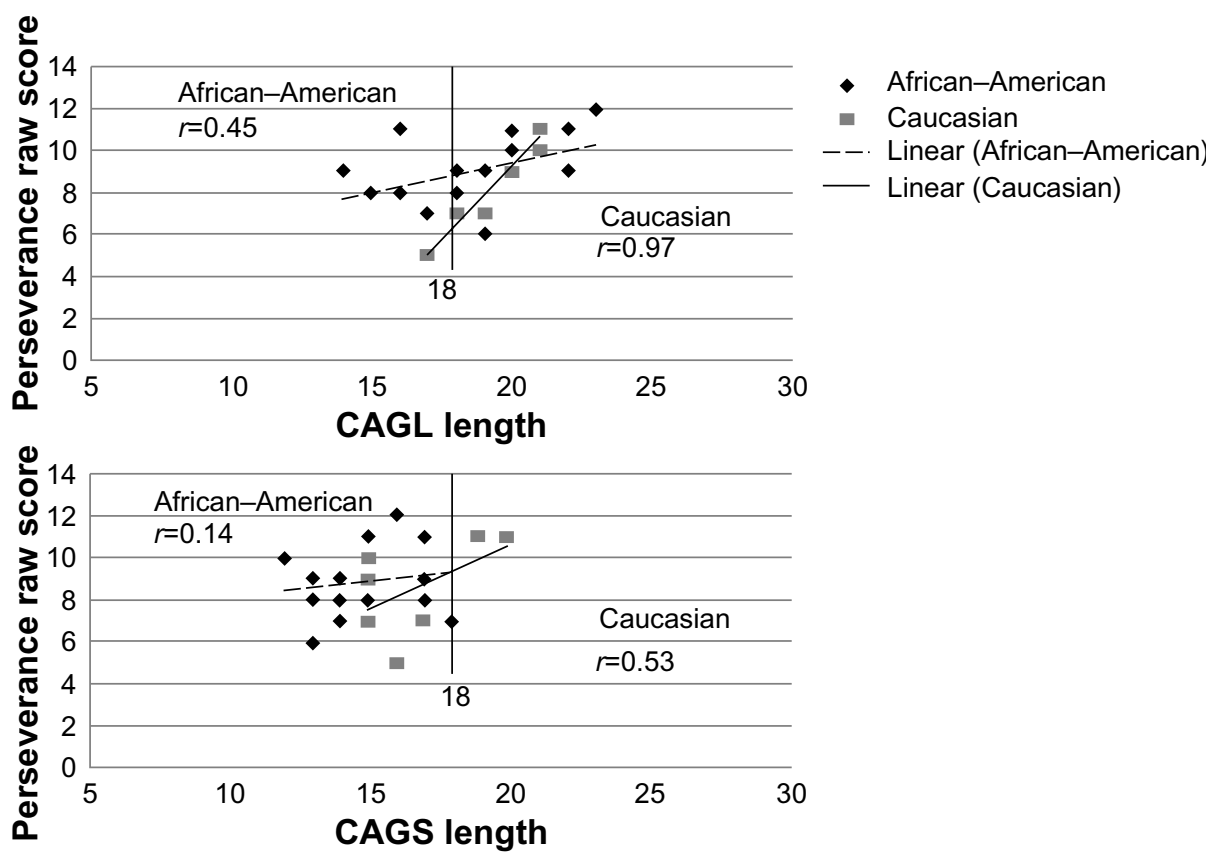

Figure 3 Spearman rank correlation between Barratt Impulsivity Perseverance scores and CAG repeat length in African-American and Caucasian women with alcoholism. Notes: The data are presented as a scatter plots of CAG repeat length for the longer and shorter alleles for all the study subjects ( $\mathrm{N}=26$ ). Trend lines have been added to illustrate the correlation between Perseverance raw scores and CAG repeat length, among both African-American and Caucasian females. The vertical demarcation line indicates the categorical divide for $\mathrm{CAG}_{\text {ave }}$ above and below 18 repeats, representing the upper quartile range (75th centile). The Spearman rank correlation coefficients ( $r$ ) are shown. Abbreviations: $A R$, androgen receptor; CAG, cytosine-adenine-guanine polymorphism; $C A G_{\text {ave }}$, average CAG repeat length; CAGL, long AR allele; CAGS, short AR allele. 


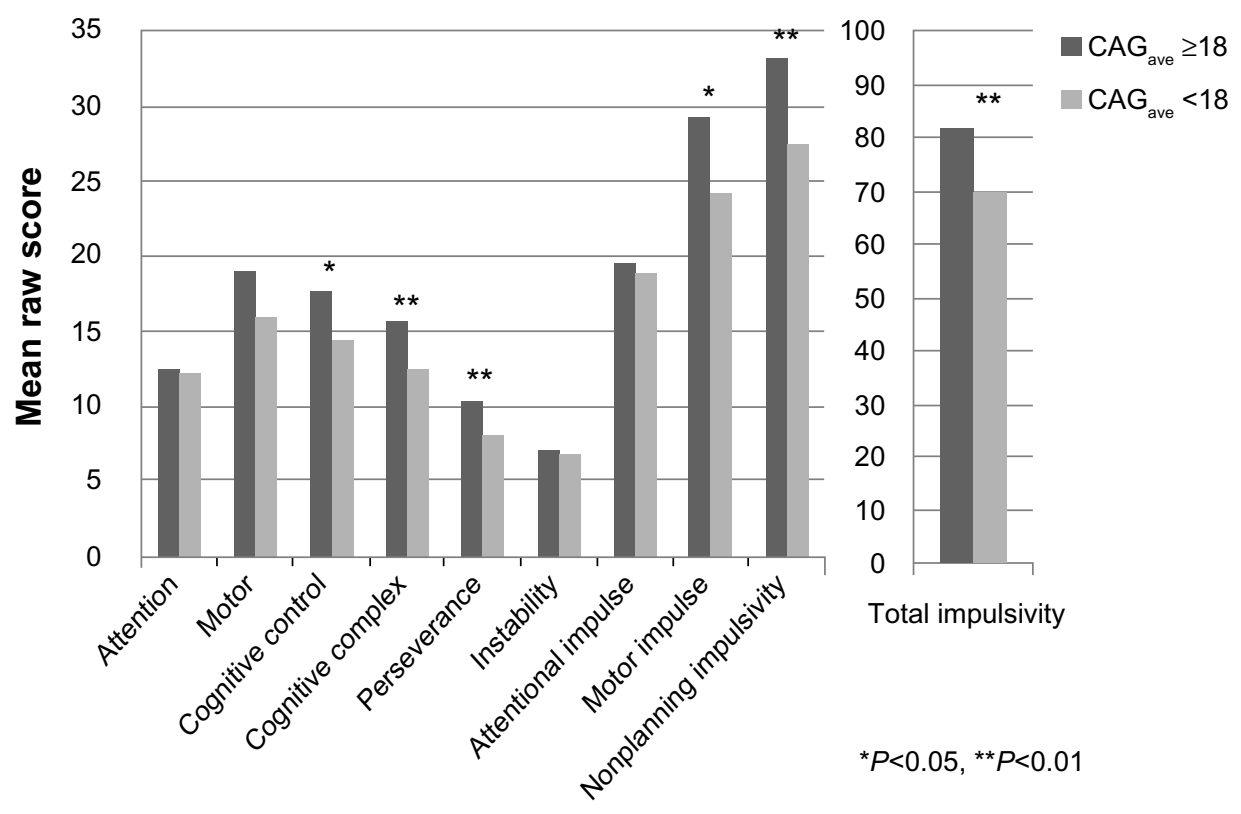

Figure 4 Barratt Impulsivity Scores for average CAG repeat length above and below 18 CAG repeats for African-American ( $N=19)$ and Caucasian ( $N=7$ ) females with alcoholism.

Notes: Mean scores were compared using a general linear model, adjusted for the effects of race, and a Bonferroni correction for multiple testing, to compare mean scores by race. Statistical significance $* P<0.05 ; * * P<0.01$.

Abbreviations: CAG, cytosine-adenine-guanine polymorphism; $\mathrm{CAG}_{\text {ave }}$, average $C A G$ repeat length.

which may influence impulsivity ratings. ${ }^{14}$ Baghaei et $\mathrm{al}^{36}$ reported elevated masculine personality traits in healthy Swedish (Caucasian) women possessing $A R$ allele $\mathrm{CAG}_{\text {ave }}>19$ repeats. The presence of masculine personality traits in these nonalcoholic subjects suggests that masculinized phenotype may result from the $A R$ gene CAG allele size and is not merely a product of alcoholic behaviors. The positive correlation between the length of $A R$ allele and impulsiveness observed in our sample supports this conclusion. The increased association in Caucasian relative to African-American females may be explained by the larger average number of CAG repeats in Caucasians who have a higher frequency of longer repeats (ie, CAG repeat lengths in the upper quartile, 75 th centile).

Further study is needed to confirm this association and elucidate the possible mechanism for the relationship. Impulsiveness in this context may arise from cross talk or the feedback effects of reduced $A R$ expression patterns on synthesis and release of hormones. Furthermore, the specific pathogenesis of SBMA (observed at trinucleotide repeat lengths $>40$ ) is modified by additional factors, such as DNA-binding, interdomain interactions, and posttranslational modification of AR. ${ }^{16}$ Even within the normal range, $A R$ gene polymorphisms are associated with variations in androgen sensitivity, which correlate with neurological and endocrine problems, including the risk of developing prostate and breast cancer and infertility. ${ }^{15,16}$ Chronic alcoholism, particularly when combined with aging, may increase the nuclear accumulation of abnormal polyglutamine-expanded AR protein encoded by CAG repeats in the high normal range (18-35 trinucleotide repeats). This may reduce the threshold for neurotoxicity and contribute to neurological dysfunction, such as increased impulsivity.

The interpretation of these findings must be tempered to account for the relatively small sample size $(\mathrm{N}=26$ females) and considered in the context of active alcohol dependence, which can directly influence hormone levels as well as cognitive function. Replicative studies including more females with alcoholism of both races are warranted. In addition, the comparison of impulsiveness scores in the general population of females without a history of alcoholism should be analyzed before $A R$ allele size is considered a potential risk factor for alcoholism and abnormal behavior.

\section{Acknowledgment}

This investigation was supported by a grant from the Hubert \& Richard Hanlon Trust; and the National Institutes of Health (NIH)-funded General Clinical Research Center Grant \#MO1RR023940 awarded to the University of Kansas Medical Center, the National Institute of Child Health and Human Development (NICHD) HD02528. 


\section{Disclosure}

The authors report no conflicts of interest in this work.

\section{References}

1. Grant BF, Dawson DA, Moss HB. Disaggregating the burden of substance dependence in the United States. Alcohol Clin Exp Res. 2011;35(3):387-388.

2. Grant JD, Vergés A, Jackson KM, Trull TJ, Sher KJ, Bucholz KK. Age and ethnic differences in the onset, persistence and recurrence of alcohol use disorder. Addiction. 2012;107(4):756-765.

3. Pulkki-Råback L, Ahola K, Elovainio M, et al. Socio-economic position and mental disorders in a working-age Finnish population: the health 2000 study. Eur J Public Health. 2012;22(3):327-332.

4. Phillips M. The alcohol drinking history. In: Walker HK, Hall WD, Hurst JW, editors. Clinical Methods: The History, Physical, and Laboratory Examinations. 3rd ed. Boston, MA: Butterworth Publishing; 1990:467-669.

5. American Psychiatric Association. Diagnostic and Statistical Manual of Mental Disorders: DSM-IV-TR. 4th ed. Washington, DC: American Psychiatric Association; 2000.

6. McKeon A, Frye MA, Delanty N. The alcohol withdrawal syndrome. J Neurol Neurosurg Psychiatry. 2008;79(8):854-862.

7. Agrawal A, Lynskey MT. Are there genetic influences on addiction: evidence from family, adoption and twin studies. Addiction. 2008;103(7):1069-1081.

8. Becker JB, Hu M. Sex differences in drug abuse. Front Neuroendocrinol. 2008;29(1):36-47.

9. Manzardo AM, Henkhaus R, Hidaka B, Penick EC, Poje AB, Butler MG. $\mathrm{X}$ chromosome inactivation in women with alcoholism. Alcohol Clin Exp Res. 2012;36(8):1325-1329.

10. Stålenheim EG, Eriksson E, von Knorring L, Wide L. Testosterone as a biological marker in psychopathy and alcoholism. Psychiatry Res. 1998;77(2):79-88.

11. Mitchell JM, Fields HL, D’Esposito M, BoettigerCA. Impulsive responding in alcoholics. Alcohol Clin Exp Res. 2005;29(12):2158-2169.

12. Lejuez CW, Magidson JF, Mitchell SH, Sinha R, Stevens MC, de Wit $\mathrm{H}$. Behavioral and biological indicators of impulsivity in the development of alcohol use, problems, and disorders. Alcohol Clin Exp Res. 2010;34(8):1334-1345.

13. Batrinos ML. Testosterone and aggressive behavior in man. Int J Endocrinol Metab. 2012;10(3):563-568.

14. Lenz B, Müller CP, Stoessel C, et al. Sex hormone activity in alcohol addiction: integrating organizational and activational effects. Prog Neurobiol. 2012;96(1):136-163.

15. La Spada AR, Wilson EM, Lubahn DB, Harding AE, Fishbeck KH. Androgen receptor gene mutations in X-linked spinal and bulbar muscular atrophy. Nature. 1991;352(6330):77-79.

16. Ackerman CM, Lowe LP, Lee H, et al; Hapo Study Cooperative Research Group. Ethnic variation in allele distribution of the androgen receptor (AR) (CAG)n repeat. $J$ Androl. 2012;33(2):210-215.

17. Westberg L, Baghaei F, Rosmond R, et al. Polymorphisms of the androgen receptor gene and the estrogen receptor beta gene are associated with androgen levels in women. J Clin Endocrinol Metab. 2001;86(6): 2562-2568.

18. Crabbe P, Bogaert V, De Bacquer D, Goemaere S, Zmierczak H, Kaufman JM. Part of the interindividual variation in serum testosterone levels in healthy men reflects differences in androgen sensitivity and feedback set point: contribution of the androgen receptor polyglutamine tract polymorphism. J Clin Endocrinol Metab. 2007;92(9):3604-3610.
19. Travison TG, Shackelton R, Araujo AB, et al. Frailty, serum androgens, and the CAG repeat polymorphism: results from the Massachusetts Male Aging Study. J Clin Endocrinol Metab. 2010;95(6):2746-2754.

20. Stanworth RD, Kapoor D, Channer KS, Jones TH. Androgen receptor CAG repeat polymorphism is associated with serum testosterone levels, obesity and serum leptin in men with type 2 diabetes. Eur J Endocrinol. 2008;159(6):739-746.

21. Aluja A, García LF, Blanch A, Fibla J. Association of androgen receptor gene, CAG and GGN repeat length polymorphism and impulsivedisinhibited personality traits in inmates: the role of short-long haplotype. Psychiatr Genet. 2011;21(5):229-239.

22. Jönsson EG, von Gertten C, Gustavsson JP, et al. Androgen receptor trinucleotide repeat polymorphism and personality traits. Psychiatr Genet. 2001;11(1):19-23.

23. Westberg L, Henningsson S, Landén M, et al. Influence of androgen receptor repeat polymorphisms on personality traits in men. J Psychiatry Neurosci. 2009;34(3):205-213.

24. Vermeersch H, T'Sjoen G, Kaufman JM, Vincke J, Van Houtte M. Testosterone, androgen receptor gene CAG repeat length, mood and behaviour in adolescent males. Eur J Endocrinol. 2010;163(2): 319-328.

25. Manzardo AM, He J, Poje A, Penick EC, Campbell J, Butler MG. Double-blind, randomized placebo-controlled clinical trial of benfotiamine for severe alcohol dependence. Drug Alcohol Depend. 2013;133(2):562-570.

26. Knop J, Penick EC, Nickel EJ, et al. Childhood ADHD and conduct disorder as independent predictors of male alcohol dependence at age 40. J Stud Alcohol Drugs. 2009;70(2):169-177.

27. Ketzenberger KE, Forrest L. Impulsiveness and compulsiveness in alcoholics and nonalcoholics. Addict Behav. 2000;25(5):791-795.

28. Dom G, Hulstijn W, Sabbe B. Differences in impulsivity and sensation seeking between early- and late-onset alcoholics. Addict Behav. 2006;31(2):298-308.

29. Allen RC, Zoghbi HY, Moseley AB, Rosenblatt HM, Belmont JW. Methylation of HpaII and HhaI sites near the polymorphic CAG repeat in the human androgen-receptor gene correlates with $\mathrm{X}$ chromosome inactivation. Am J Hum Genet. 1992;51(6):1229-1239.

30. Butler MG, Theodoro MF, Bittel DC, Kuipers PJ, Driscoll DJ, Talebizadeh Z. X-chromosome inactivation patterns in females with Prader-Willi syndrome. Am J Med Genet A. 2007;143(5):469-475.

31. Bittel DC, Theodoro MF, Kibiryeva N, Fischer W, Talebizadeh Z, Butler MG. Comparison of X-chromosome inactivation patterns in multiple tissues from human females. J Med Genet. 2008;45(5):309-313.

32. Bonett DG, Wright TA. Sample size requirements for estimating Pearson, Kendall and Spearman correlations. Psychometrika. 2000;65(1):23-28.

33. Hatcher D, Daniels G, Osman I, Lee P. Molecular mechanisms involving prostate cancer racial disparity. Am J Transl Res. 2009;1(3):235-248.

34. Irvine RA, Yu MC, Ross RK, Coetzee GA. The CAG and GGC microsatellites of the androgen receptor gene are in linkage disequilibrium in men with prostate cancer. Cancer Res. 1995;55(9):1937-1940.

35. Stanford MS, Greve KW, Boudreaux JK, Mathias CW, Brumbelow JL. Impulsiveness and risk-taking behavior: comparison of high-school and college students using the Barratt Impulsiveness Scale. Pers Individ Dif. 1996;21(6):1073-1075.

36. Baghaei F, Rosmond R, Landén M, et al. Phenotypic and genotypic characteristics of women in relation to personality traits. Int J Behav Med. 2003;10(4):365-378. 
Advances in Genomics and Genetics

Dovepress

\section{Publish your work in this journal}

Advances in Genomics and Genetics is an international, peer reviewed, open access journal that focuses on new developments in characterizing the human and animal genome and specific gene expressions in health and disease. Particular emphasis will be given to those studies that elucidate genes, biomarkers and targets in the development of new or improved therapeutic interventions. The journal is characterized by the rapid reporting of reviews, original research, methodologies, technologies and analytics in this subject area. The manuscript management system is completely online and includes a very quick and fair peer-review system. Visit http://www.dovepress.com/ testimonials.php to read real quotes from published authors.

Submit your manuscript here: http://www.dovepress.com/advances-in-genomics-and-gene-expression-journal 